\title{
体内埋込型ワイヤレス皮質脳波計測装置の開発 ーファーストプロトタイプの性能評価一
}

\section{Development of an Implantable Wireless ECoG Recording Device}

- Performance Investigation of the first Prototype -

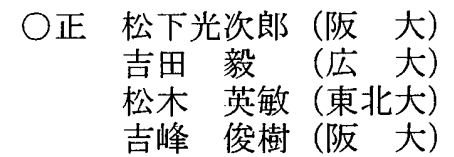

平田 雅之 (阪 大) 加藤健太郎 (東北大) Morris Shyne (阪大) \begin{tabular}{lll} 
鈴木 & 隆文 & (東 $大)$ \\
佐藤 & 博文北大) \\
後藤 & 哲 & (阪 \\
\hline
\end{tabular}

Kojiro MATSUSHITA (Osaka Univ.), Masayuki HIRATA (Osaka Univ.), Takafumi SUZUKI (Tokyo Univ.), Takeshi YOSHIDA (Hiroshima Univ.), Kentaro KATO(Tohoku Univ.), Hirofumi SATO (Tohoku Univ.), Hidetoshi MATSUKI (Tohoku Univ.), Morris SHYNE (Osaka Univ.), Tetsu GOTO (Osaka Univ.), Toshiki YOSHIMINE (Osaka Univ.)

Brain Machine Interface (BMI) is a system that assumes user's intention by analyzing user's brain activities and control devices with the assumed intention. It is considered as one of prospective tools to enhance paralyzed patients' quality of life. In our group, we especially focus on ECoG (electro-corti-gram)-BMI, which requires surgery to place electrodes on the cortex. We try to implant all the devices within the patient's head and abdomen and to transmit the data and power wirelessly. Our device consists of 5 parts: (1) High-density multi-electrodes with a 3D shaped sheet fitting to the individual brain surface to effectively record the ECoG signals; (2) A small circuit board with two integrated circuit chips functioning 128 [ch] analogue amplifiers and A/D converters for ECoG signals; (3) A wireless data communication \& control device with the PC installing its dedicated software. At the present stage, the Bluetooth chips are temporally applied; (4) A non-contact power supply transmitting electrical power minimum 4 [W] to the device $10-40[\mathrm{~mm}]$ away. We developed those devices, integrated them, and, investigated the performance.

Key Words: Brain Machine Interface, ECoG,, Bio-signal Sensing.

\section{1. 精言}

近年，ブレイン・マシン・インターフェース（BMI）研究開 発において，皮質脳波が注目されている。「皮質脳波」とは, 脳の表面にて計測される脳波であり，その計測は，難治性疼 痛・難知性てんかんを有する患者の治療・検查を行う場合に 認められる医療技術となっている．また皮質脳波は，脳に刺 しこむ針電極 [1] とは異なり脳表面に留置するのみであるこ とから低侵襲で安全性も確保することができ, Pistohl ら[2] が皮質脳波解析により腕の二次元動作軌跡を抽出したことか らわかるように，情報処理の適用により BMI の実用化の可能 性を有している.

しかしながら，現状のヒトの皮質脳波計測は，脳表面に留 置された電極が体外の PC と直接的に有線接続されるため, 感 染症防止の理由から二週間の計測に限られている。 そのよう な理由から皮質脳波 BMI 実用化のためには，長期計測を可能 とする体内埋込型の皮質脳波計測装置 (Fig. 1) の開発が必要 である。

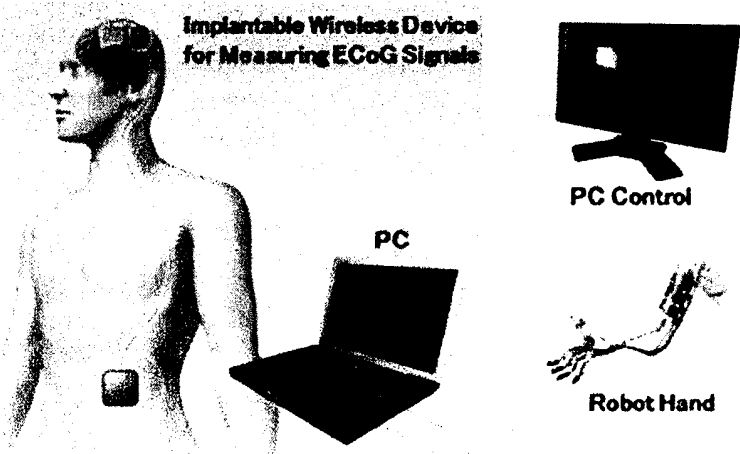

Fig. 1 Conceptual diagram of an implantable device for BMI

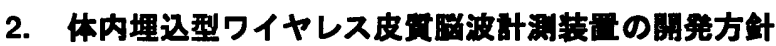

体内埋込型皮質脳波装置は装置を体内に完全に埋め込むた め, 下記項目に示すように, 皮質脳波計測装置の超小型化, データ・電力送信のワイヤレス化が課題となる.

（1）皮質脳波用電極の小型化

(2) 皮質脳波計測用集積回路チップ\&基板の開発

（3）上記回路基板を収納する頭蓋骨型・頭部ケーシング

（4）小型かつ汎用の無線デー夕通信装置の開発

(5) 皮下に給電可能な小型非接触給電装置の開発

各専門分野の研究者ら・企業と共に, 体内埋込型ワイヤレ ス皮質脳波計測装置行っており，本稿は，第 1 プロトタイ プの開発の報告である (Fig. 2, Table 1).

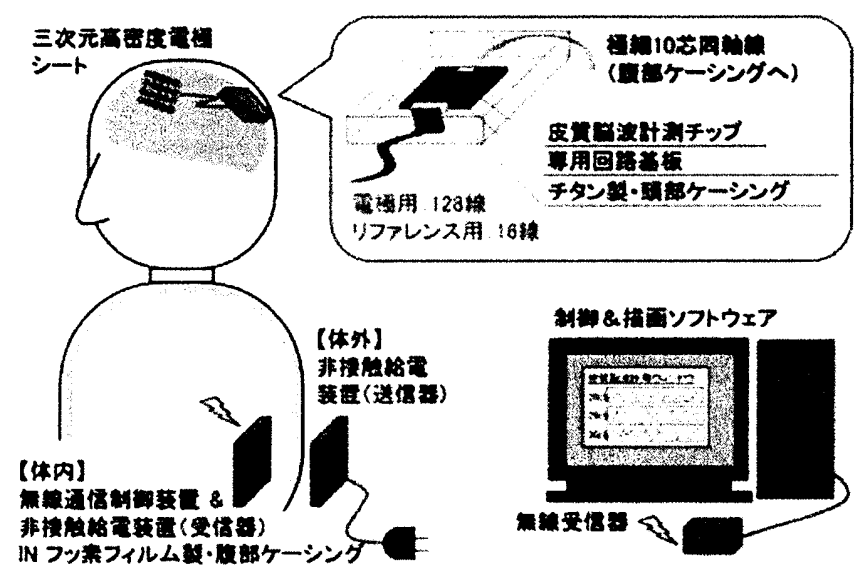

Fig. 2 Conceptual diagram of the proposed implantable device 
Table 1 Developer List

\begin{tabular}{|c|c|c|}
\hline 装置の配置 & 開発パート & 開発担当 \\
\hline \multirow{4}{*}{ 頭部埋込 } & 三次元高密度電極 & 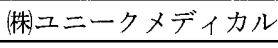 \\
\hline & 皮質脳波計測チップ & \multirow{2}{*}{ 検エイアールテック } \\
\hline & チップ用回路基板 & \\
\hline & 頭部ケーシング & 侏飛鳥電機製作所 \\
\hline \multirow{4}{*}{ 腹部埋込 } & 腹部ケーシング\&配線 & 㫼潤工社 \\
\hline & 制御装置 & \multirow{2}{*}{ 侏計数技研 } \\
\hline & 無線通信装置 & \\
\hline & 非接触給電装置 (受信器) & 東北大学 \\
\hline \multirow{2}{*}{ 体外配置 } & 非接触給電装置（送信器） & 松木・佐藤研究室 \\
\hline & 計測制御用 P C & 㑣計数技研 \\
\hline
\end{tabular}

なお，装置が頭部と腹部に分けて別々に埋め込まれる形式で ある利用を下記項目にまとめる。

(1) 無線通信が脳波計測に影響を与えないように分離

(2) 非接触給電装置が生じる磁場が脳波計測・頭部に影響を 与えないよう分離

(3) 将来の計画において, 無線制御器とバッテリの性能改善 在前提としており，交換が比較的容易な腹部に配置

\section{3. 第 1 プロトタイプ}

体内埋込型ワイヤレス皮質腦波計測装置（第1プロトタイ プ）の全体図在Fig. 3 に示す。

頭部埋込装置は, 三次元高密度電極シート・皮質脳波計測 回路・チタン製頭蓋骨型ケーシングにて構成される.Fig3 の 右側の fMRI 計測から得られたヒトの頭部形状データに基づ き 3 次元プリンタにより製作された頭蓋骨・脳モデルに配置 される.

腹部埋込装置は, 無線通信制御器・非接触給電装置にて構 成される.Fig. 3 の左側に示される円形形状のケーシングにシ リコン樹脂とフッ素フィルムにて封止されている。なお腹部 ケーシングのサイズは, 現状, 目標としている直径 $100 \mathrm{~mm}$ よ りも大きなサイズとなっているが，現在開発中のブロトタイ プにおいては，無線通信装置の小型化・消費電力の低減化 試みており，更に小型になる。

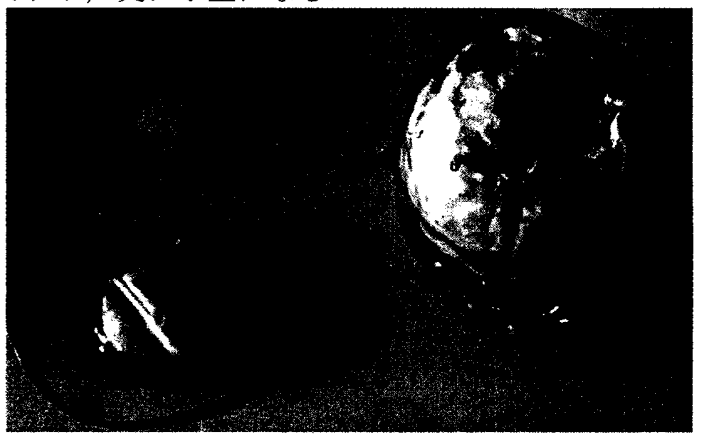

Fig. 3 Appearance of the first prototype.

\section{1 三次元高密度党植シート}

三次元高密度電極は, 合計 $144[\mathrm{ch}]$ （計測用電極 $128 \mathrm{ch,} \mathrm{リ}$ ファレンス電極 $16 \mathrm{ch}$ ）によって脳表面に流れる微弱な信号女 皮質脳波計測回路に入力する電極群である，提案する電極シ 一トは，より詳細な皮質脳波を計測可能とするため，Fig. 4(a) に示すように, 通常の電極シートよりも電極の高密度化を行 った（電極サイズ老小型に，から，電極間距離をより短く）.
しかしながら，従来の平らな電極シートの高密度化を行う 場合，小型化した多くの電極が凹凸のある脳表面に密着する ことが困難であることがわかった，そのため，利用者個々の 脳表面形状に対応可能とするように，fMRI 計測から脳表面形 状得て, 利用者の脳表面形状にフィットする三次元電極シ 一トを製作するプロセスをも構築した（Fig. 4(b)).

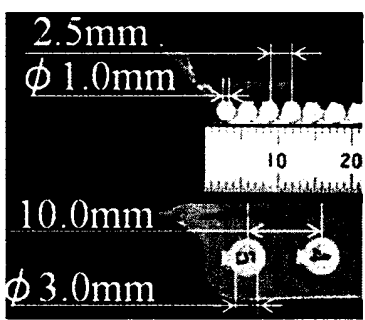

(a)

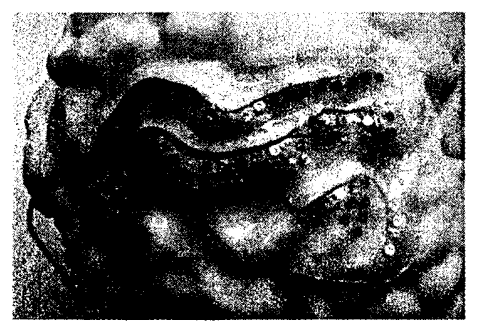

(b)
Fig. 4 3D High-Density Electrode Sheet. (a)Comparizon between the conventional electrode sheet (top) and the proposed electrode sheet (bottom). (b) The proposed electrode sheet on a brain model, which made of a 3D printer.

\section{2 皮贯膦波社測回路}

皮質脳波計測回路は，入力された脳波信号の増幅・デジタ ル変換・シリアルデータ化を行い, 腹部埋込装置へとシリア ルデータ送信を行う。そのため, 電極線 $144 \mathrm{ch}$ (皮質脳波計測

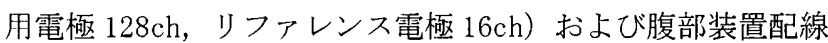

（10 線）が接続される．皮質脳波計測回路は，Fig. 5 に示さ れるように. 皮質脳波 $64 \mathrm{ch}$ 計測用に製作された 5 ミリ角の集 積回路チップが専用回路基板に取り付けられ，それら 2 セッ トが接続されている構成となる.なお, 集積回路チップ (1 枚) の仕様を, Table 2, Fig. 6 に示す.

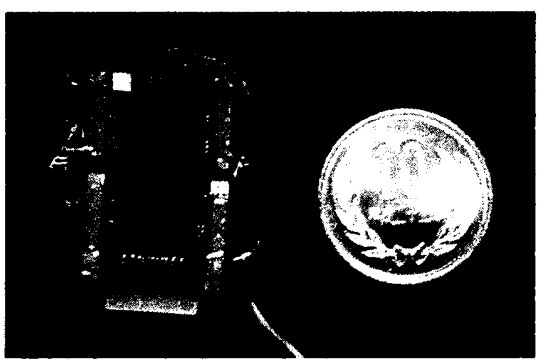

Fig.5 Appearance of the ECoG recording circuit.

Table 2 Specification of the integrated circuit chip for recording ECoG signals.

\begin{tabular}{|c|c|}
\hline 項目 & n \\
\hline 信号入力 $\mathrm{CH}$ & 64[ch]（2 チップ構成時 128[ch]） \\
\hline バンドバスフィルタ & $\begin{array}{c}\text { 低域設定: } 0.1[\mathrm{~Hz}] / 1[\mathrm{~Hz}] / 10[\mathrm{~Hz}] \\
\text { 高域設定 : } 100[\mathrm{~Hz}] / 500[\mathrm{~Hz}] / 1000[\mathrm{~Hz}]\end{array}$ \\
\hline アンプ電压利得 & $40[\mathrm{~dB}] / 50[\mathrm{~dB}] / 60[\mathrm{~dB}] / 70[\mathrm{~dB}] / 80[\mathrm{~dB}]$ \\
\hline 入力振幅レンジ & $1 \mathrm{uV} \sim 1 \mathrm{mV}$ \\
\hline $\mathrm{ADC}$ 個数 & 2 個 \\
\hline ADC 分解能 & 12bit \\
\hline サンプリングレート & $250[\mathrm{Sps} / \mathrm{ch}] / 500[\mathrm{Sps} / \mathrm{ch}] / 1000[\mathrm{Sps} / \mathrm{ch}]$ \\
\hline シリアルデータ送信速度 & $200[\mathrm{kbps}] / 400[\mathrm{kbps}] / 800[\mathrm{kbps}]$ \\
\hline 消費電力 & $10[\mathrm{uW} / \mathrm{ch}]$ \\
\hline チップ面積 & $5[\mathrm{~mm}] * 5[\mathrm{~mm}]$ \\
\hline CMOS プロセス & 0.18 [um] \\
\hline
\end{tabular}




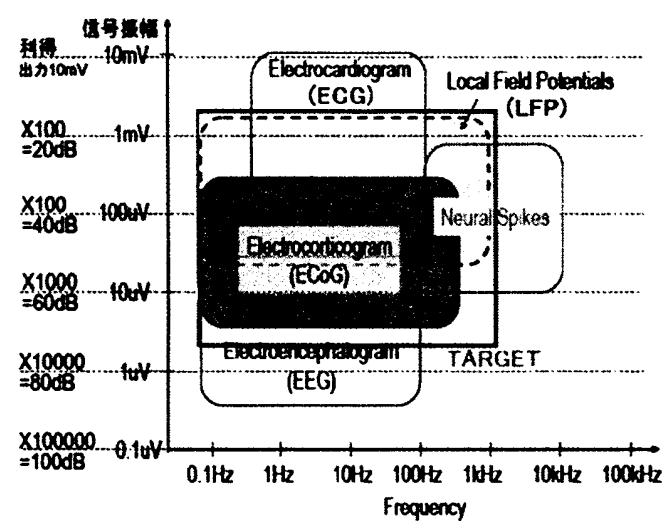

Fig. 6 Target range of the integrated circuit chip.

\section{3 チタン酷・蓋骨型ケーシング}

脳表面に電極者留置する手術においては，頭蓋骨の一部が 取り除かれ，後日，七ラミックなど生体適合素材にて製作さ れるカスタムメイドの代替骨が利用される。 ここで本開発で は，できうる限りコンパクトな装置の留置を考慮し，頭部埋 込装置類を代替骨内に収納寸る頭部ケーシング石指した。

Fig.7(Top)に示されるように，まずはfNRI 計測からヒトの 頭部形状デー夕を得て，そのデータを $\mathrm{CAD}$ データに変換，頭 蓋骨形状のケース構造在設計した. Fig. 7 (Bottom) は，乙の 設計データ基に，チタンから削り出した頭蓋骨形状のケー スレである。
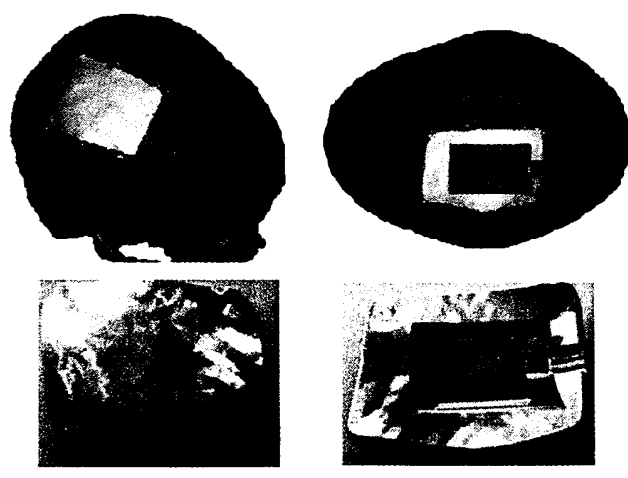

Fig. 7 A skul1-shaped case. (Top) CAD data based on fMRI data. (Bottom) Appearance of the real titanium case.

\section{4 年湶制御器}

無線制御装置をFig. 7 に示す。サイズは $50 \mathrm{~mm}$ 角内に収まる 8 角形であり，その役割は（1）頭部装置（皮質脳波計測回路） から送信されるシリアルデータ在受け取り, UART データに変 換し，体外のPCに送信，（2）体外 PC から情報を受け取り， 皮質脳波計測回路の制御 (設定变更)，上なる。

無線制御装置は, Fig. 8 に示されるように, CPLD・CPU・ Bluetoothから構成され，CPLDにおいてはシリアルデー夕を パラレルデータに変換し，CPUに転送している。 CPUでは，パ ラレルデータとして皮質脳波情報を受け取り, Bluetoothや USB に対応するUART データに変換し，体外 PC に送信する。ま た，体外 PC から情報を受け取る場合, UART データにより受け 取り，皮質脳波計測回路一上制御信号送る。な掞，皮質脳 波計測回路の設定項目は，記録周波数 $(250 \mathrm{~Hz} / 500 \mathrm{~Hz} / 1000 \mathrm{~Hz})$, カットオフ周波数 $(0.1 \mathrm{~Hz} / 1.0 \mathrm{~Hz} .10 \mathrm{~Hz}-240 \mathrm{~Hz})$ ，ゲイン $(40 \mathrm{~dB} / 60 \mathrm{~dB} / 80 \mathrm{~dB})$ などが挙げられる.

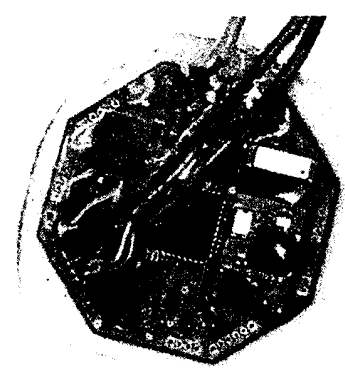

$50 \quad 60 \quad 70 \quad 100$

Fig. 7 Appearance of the wireless controller.

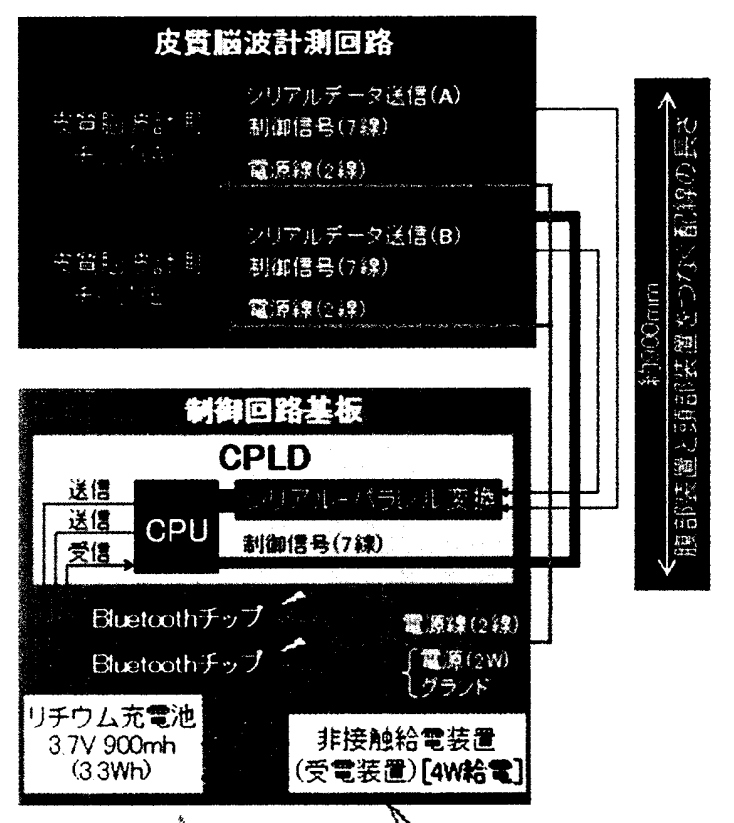

皮裙踏肪! $10-40 \mathrm{~mm}$

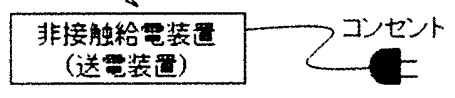

Fig. 8 System flowchart of the implantable device.

\section{5 非接住佮而洼置}

非接触電力供給の要求仕様は，(1) 体内外が皮膚・脂肪によ り遮られている空間（体外装置から体内装置の距離） $10 \mathrm{~mm}$ から 40mm までと想定し, その範囲において 4 [W]の電力供給孝 確保 (なお，体内埋込装置部のみの消費電力は $2[\mathrm{~W}]$ であるが, 非接触給電装置の使用中に同時並行にて内蔵バッテリの電力 在行えるように $2[\mathrm{~W}]$ 在加算し，合計 $4[\mathrm{~W}]) ，(2)$ 体内にて火傷 しないよう装置表面の発熱孝 36 度以下に抑えること, (3) 腹 部に留置するため, 負荷がかからないよう極力小型化, が举 げられる。

Fig. 9 に示される非接触給電装置は, 非接触距離が $40 \mathrm{~mm}$ に おいても $4[\mathrm{~W}]$ 給電可能であり, Fig. 10 のサーモグラフィ図に 示されるように装置表面温度も 36 度未満（非接触距離 $10 \mathrm{~mm}$ )

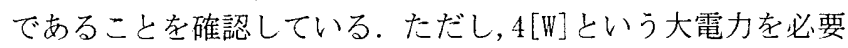
と寸るため, 構成要素であるコンデンサと DCDC コンバータの 小型化が困難であったため，サイズは $80 \mathrm{~mm} * 80 \mathrm{~mm} * 12 \mathrm{~mm}$ となっ ている. 次のプロトタイプは, 消費電力が $400 \mathrm{~mW} \sim 800 \mathrm{~mW}$ と, 約 $1 / 10 \sim 1 / 5$ に低減されるため, 小型化が可能となっている. 

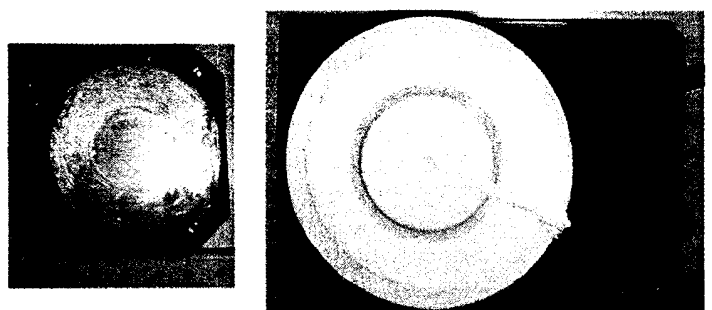

Fig. 9 Appearance of a set of non-contact power supply.

(left) Receiver, (right) Transmitter.

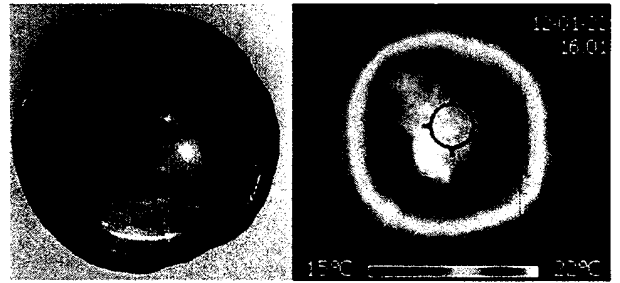

Fig. 10 Temperature Investigation with a thermography.

\section{4. 性能検泟实験}

性能検証は，皮質脳波計測のみに注目し，専用のPCソフト ウェアでの制御含めての皮質脳波信号のリアルタイム計測 \&描画の確認を行った。

\section{1 实臥設定}

Fig. 11 に，実験セットアップを示す。本セットアップは， 皮質脳波計測回路 1 セット上Bluetooth（1 個）取り付けて いる無線制御器 1 セットの簡便な構成とした。 また, 実際の皮 質脳波信号椺保は困難であることと，各振幅・各周期に対 する検証を置こう必要性があったため，疑似脳波信号とみな せる 8uV から 160uV までの振幅を有する正弦波出力するフ アンクションジェネレータを自作し，入力信号とした

(Fig. 12).
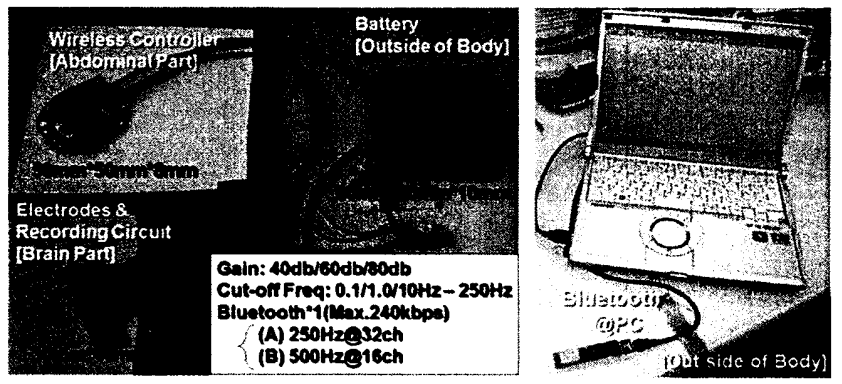

Fig. 11 Experimental setup 1: the developed device.

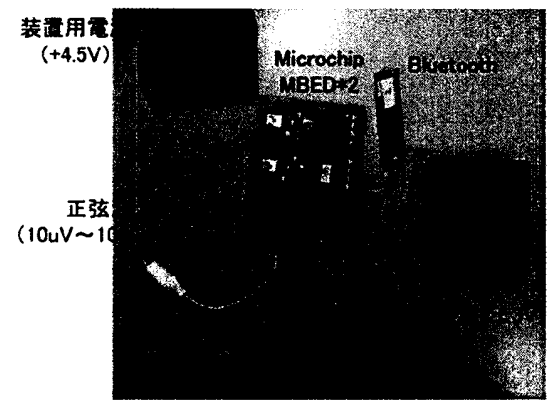

(a)

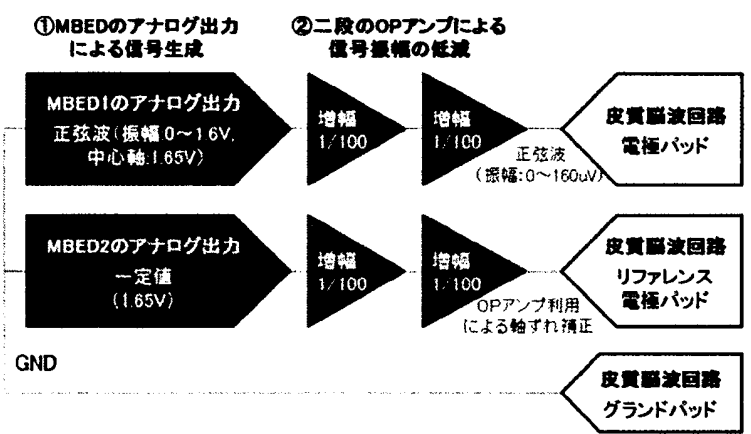

(b)

Fig. 12 Experimental setup 2: an original function generator device. (a) Appearance. (b) System flowchart.

\section{1 实驗結果}

正弦波 (8uV/160uV, 10Hz) 基準として, PCソフトウェア で異なる設定值一ゲイン $(40 \mathrm{db} / 60 \mathrm{db} / 80 \mathrm{db})$ ・カットオフ・記 録周波数 $(250 \mathrm{~Hz} / 500 \mathrm{~Hz} / 1000 \mathrm{~Hz})$ 一にて，正弦波索計測した。 その結果, PCソフトウェアが正しい設定值にてリアルタイム 描画およびデータ保存が実現していることを確認した。

Fig. 13 に示される図梳, 14ch に正弦波 $(160 \mathrm{uV}, 10 \mathrm{~Hz})$ を入力し た時の計測 (ゲイン : 40db，カットオフ : 0. 1-240Hz，記録周 波数: $500 \mathrm{~Hz})$ 結果である.

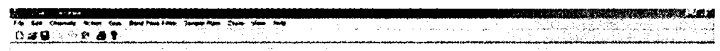

Fig. 13 Recording a sine wave with the PC software.

\section{5. まとめ}

本研究では，皮質脳波 BMI 在目指して，体内埋め込み型皮 質脳波計測装置開発している。本稿は，その第 1 プロト夕 イプの構成の説明，および，皮質脳波計測に対忘可能である ことを示した。

\section{6. 政辞}

文部科学省 脳科学研究戦略推進プログラム 研究開発拠点 整備事業 (課題 A)「ブレイン・アシン・インターフェース (BMI) の開発」〈http://brainprogram. mext.go.jp/〉の支援により実 施されています。また本開発に協力いただいている(㷛ユニニー クメディカル・㑣エエイアールテック・㑣)飛鳥電機製作所・株 潤工社・㑣計数技研に感謝の意在表する。

\section{文 献}

[1] Meel Velliste, Sagi Perel, M. Chance Spalding, Andrew S. Whitford \& Andrew B. Schwartz. Cortical control of a prosthetic arm for self-feeding. Nature, pp 1098-1101 (2008).

[2] T. Pistohl, T, Ball, A. Schulze-Bonhage, A. Aertsen, C. Mehring: Prediction of arm movement trajectories from ECoG-recordings in humans. J. Neurosci. Methods 167, pp 105-114 (2008). 